zona meridional. Mientras en la primera zona, más elevada, hemos observado que la conservación de las ruinas puede ser más completa, en todo el área norte hemos podido constatar la progresiva intrusión del asentamiento actual de Piura la Vieja en el área de interés arqueológico. Puede verse como las nuevas edificaciones se superponen a buena parte del tercio meridional de la antigua ciudad española y como se emplea la zona de contacto entre las ruinas y el actual asentamiento como cantera de extracción de materiales de construcción para las viviendas: fundamentalmente canteras de tierra para la fabricación de adobe y recogida de mampuestos de las antiguas construcciones virreinales para la ejecución de zócalos de piedra. El reconocimiento efectuado en el área de contacto entre las ruinas y el asentamiento actual ha mostrado la abundancia de restos arquitectónicos de verdadero interés a la vista del espesor y características constructivas de los muros que, de forma constante, se solapan con las zonas de edificación de las viviendas actuales, de los corrales y de los establos y almacenes. Toda la zona de ruinas muestra en definitiva gran cantidad de muros de mampostería de piedra de diferente tipología, pudiendo distinguirse básicamente entre los de una y los de dos hojas, con relleno interior de tierra y cascote, y según los espesores, desde los $60-80 \mathrm{~cm}$ al metro y medio (dos metros en casos excepcionales). De los sondeos estratigráficos llevados a término así como del resto de los trabajos efectuados hasta diciembre del 200 I puede concluirse, en primer lugar, que se confirman plenamente las descripciones de Salinas de Loyola (cimientos de piedra, y lo demás de adobes y tapias, y cal, y ladrillo, y las cobijas de paja, como llueve poco...)

El carácter pompeyano de las ruinas de San Miguel de Piura parece permitir la reconstrucción casi completa del plano de la ciudad que, como los restos de las casas, corresponde exactamente al original de mediados del siglo XVI y puede potencialmente pro- porcionarnos mucha más información sobre la ideología y la estructura espacial y visual aplicada por los conquistadores en el Nuevo Mundo que otras ciudades mejor conservadas y mayores que han sufrido, sin embargo, innumerables modificaciones con el paso del tiempo. Desde el punto de vista arqueológico las ruinas de la ciudad virreinal de San Miguel de Piura en Piura la Vieja constituyen lo que un códice para un historiador $y$, como tales, deben ser ineludiblemente puestas en valor y preservadas, tanto para su estudio científico y su excavación arqueológica, como para su posible recuperación y muestra al público en el marco de un proyecto de rehabilitación integral y desarrollo sostenible de toda la comarca, una de las menos conocidas del norte del Perú.

Luis de Villanueva Domínguez Fernando Vela Cossío

Profesores de la Escuela Técnica Superior de Arquitectura de Madrid

\title{
La investigación sobre el centro histórico de Larache, un ejemplo de cooperación con Marruecos
}

La convocatoria de ayudas para la investigación en materias relacionadas con el Programa Regional de Planeamiento de Centros Históricos de Andalucía, se recoge en la Orden de 14 de Octubre de 1996, de la Consejería de Obras Públicas y Transportes y la de Cultura, publicada en el Boletín Oficial de la Junta de Andalucía n 124, de 29 de Octubre de 1996.

Dentro de los temas de interés prioritario, expresados en la citada Orden, se consideraban aquellos que pudieran abordar los Centros Históricos de Andalucía-Magreb, dado que, tal como expresaba el texto de la convocatoria: "Parte de los Centros Históricos de Andalucía, por su origen y evolución, presentan características similares a algunos de los de las ciudades de la zona Norte de Marruecos y resto del Magreb, en sus condiciones de emplazamiento, estructura urbana, tipología arquitectónica, etc.". Partiendo de esta premisa, los proyectos habían de estar orientados hacía el conocimiento de los centros históricos y la normativa o planeamiento urbanístico de aplicación en la mencionada área geográfica.
Tras el análisis de las características de la convocatoria, unido al interés objetivo del equipo de investigación, presentamos en Noviembre de 1996, el proyecto de investigación: "Centros históricos del Magreb: el norte de Marruecos". En el mismo señalábamos que teniendo en cuenta la brevedad de plazo para la ejecución del trabajo, un año, lo cual hacía casi imposible abarcar todo el ámbito geográfico del Magreb con un conocimiento directo, se proponía el análisis conjunto de los Centros Históricos marroquíes de las ciudades de Tánger, Tetuán, Larache, Alcazarquivir, Uazán y Chefchauen, desde la perspectiva de la normativa urbanística que pudiera existir en ellos, entre otros objetivos.

Posteriormente pudimos comprobar que, tal como ya habíamos previsto en parte en la redacción del proyecto, sólo la simple obtención de una documentación inicial para poder comenzar a trabajar, encerraba otros parámetros de resolución administrativa diferentes a los de nuestro país, por lo que pronto intuimos que la aproximación a la realidad y conocimiento a nivel técnico de to-

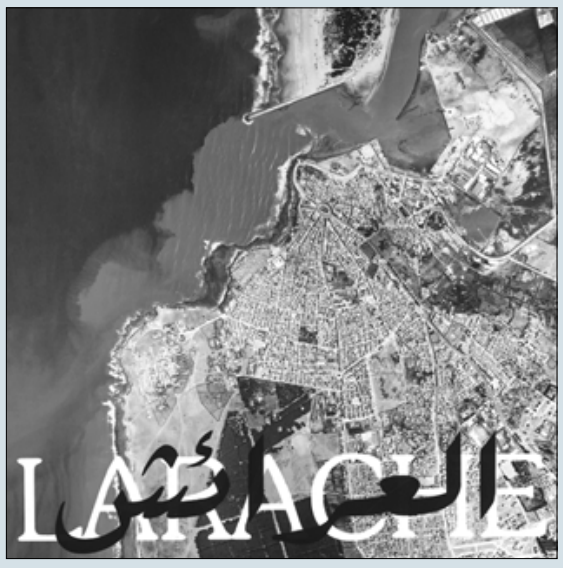

das y cada una de las ciudades de este territorio del Norte de Marruecos, desde la perspectiva urbanística e histórica, resultaba una laboriosa empresa que, pese a nuestro interés, debería ser llevada a cabo de una forma gradual y escalonada en el tiempo, con una metodología de trabajo ajustada.

Analizados los condicionantes de tipo logístico y en concordancia con nuestra coordina- 
dora del trabajo, Da Ángeles Gil, del servicio de Planeamiento Urbanístico de la Dirección General de Urbanismo y Ordenación del Territorio, se fueron incardinando los objetivos generales de nuestro programa de investigación centrándonos en la ciudad de Larache por concurrir en ella una serie de circunstancias que más adelante serán expuestas.

Desarrollado el proyecto entre 1997 y 1998 , en el otoño de este año se entregó la memoria de investigación una vez finalizados los trabajos. La positiva valoración del mismo por parte de la Consejería de Obras Públicas y Transportes de la Junta de Andalucía propició en la primavera de 1999 la entrega oficial de copias del mismo al Ayuntamiento de Larache y a la Province (gobierno provincial). Mientras tanto, en base a los contenidos del trabajo de investigación, se nos encomendó la preparación de una publicación en formato libro que recogiese las principales aportaciones del trabajo, así como la elaboración de los contenidos para el montaje de la exposición: Larache. Evolución Urbana.

Inaugurada ésta en octubre de 1999, supuso un gran acontecimiento en la vida cultural de la ciudad. Desde aquí fue desplazándose entre los años 1999 y 2000 por Tánger, Tetuán, Chefchauen, Ceuta y Vejer de la Frontera. Los contenidos, desarrollados mediante ocho grandes paneles, estaban ilustrados con cartografía histórica, planimetría de evolución urbana y fotografías, completados con un extenso friso de fotografías realizadas por Atín Haya. Los textos se redactaron bilingües castellano-árabe.

El contenido de esta exposición ha sido editado en formato CD por parte de la Consejería de Obras Públicas y Transportes de la Junta de Andalucía. Coincidiendo con la fecha de la inauguración de la exposición en la ciudad, se firmó el acuerdo de cooperación de la Junta de Andalucía con el Ayuntamiento de Larache mediante el cual se han ido desarrollando actuaciones en el plano del urbanismo y en el de la rehabilitación arquitectónica como es el caso de las obras que actualmente se llevan a cabo en el Mercado Central.

Posteriormente, en el otoño de 200I, verá la luz el libro también titulado: Larache. Evolución Urbana, editado por las Consejerías de Obras Públicas y Cultura de la Junta de Andalucía. Dicha obra de cuidada edición, cuyos textos se presentan bilingües castellano- árabe, recoge los contenidos más esenciales del trabajo de investigación. Estos se estructuran a partir de los siguientes capítulos: Introducción; Encuadre histórico y evolución urbana; Información y diagnóstico; Orientaciones para la intervención; Catálogo de elementos de interés arquitectónico y urbano: Ciudad Antigüa y Ciudad Moderna; Apéndice y Bibliografía.

Indudablemente, las buenas relaciones entre la Comunidad Autónoma andaluza y el Reino de Marruecos en el marco de la cooperación internacional en materia de urbanismo, arquitectura y cultura, con los ejemplos de Tetuán y Chefchauen entre otros, y el fomento de este entendimiento con los sucesivos encuentros y actividades formativas entre técnicos de las administraciones de ambas comunidades, han ayudado a que por parte de las diferentes entidades locales y provinciales del país vecino, se nos haya ido facilitando nuestro trabajo. El desarrollo de este modelo de actuación progresivamente ha ido dando sus frutos a la vez que ha servido para hacer una pública llamada de atención sobre el rico patrimonio que poseen, para ir creando una conciencia generalizada del interés que encierran y, en definitiva, para alentar a las administraciones implicadas a que velen por su protección y faciliten la puesta en valor de estos Centros Históricos, lo que repercutirá en su conservación y revalorización.

\section{Definición del área de estudio}

Desde su inicio, el proyecto de investigación no se planteó como un ejercicio teórico que finalmente sólo pudiera aportar unas conclusiones que pasaran a engrosar el conjunto de una bibliografía sobre el tema. En la definición de los objetivos nos propusimos ser concretos, pues a priori teníamos la certeza de que ésta sería a la postre una virtud del proyecto de investigación que habría de dar como consecuencia resultados aplicables y más cercanos a la realidad física del objeto de estudio. Ello no quiere decir que se renunciara al necesario debate en un proceso que en todo caso, y a pesar de la concisión con la que se planteaba, ha debido ser el resultado de reflexiones previas y su constatación en la aplicación práctica.

Otro de los objetivos ha sido trabajar desde el primer momento en cooperación con los investigadores y técnicos marroquíes buscan- do un intercambio de experiencias. Progresivamente se ha conseguido conocer además algunas realidades que influyen decisivamente en el entendimiento de la ciudad islámica, forma de utilizarla, de gestionarla, de conocer las necesidades reales de sus habitantes, de entender el concepto de propiedad, de espacio público y las decisiones que le afectan a partir de los fundamentos de derecho islámico, etc. Además se ha dejado constancia de que los estudios y posibles intervenciones que se llevan actualmente a cabo logran traspasar el límite de su simple valor intrínseco, convirtiéndose en iniciativas que contribuyen al desarrollo de las actuaciones sobre Centros Históricos, en particular dentro de un marco de cooperación e intercambio, necesario para el progreso cultural y social de la zona.

Tras una serie de visitas al conjunto de las ciudades antes mencionadas, el análisis de los estudios e iniciativas existentes, y a tenor de los objetivos del proyecto, su viabilidad y marco temporal para su realización, se eligió, como ya ha quedado dicho, la ciudad de Larache.

Dicha ciudad reúne una serie de características que aportan suficiente contenido y diversidad al trabajo, que podemos resumir en:

I. Existencia de un entorno formado por un paisaje cultural en el que sobresalen la ciudad púnico-romana de Lixus y el más reciente enclave estratégico de la propia ciudad de Larache sobre el entorno natural de la desembocadura del río Lucus al Atlántico y zonas litoral y prelitoral próximas. Todo ello dentro de un territorio sin grandes alteraciones físicas donde aún persisten usos y actividades tradicionales.

2. Localización en Larache de una serie de estratos temporales claramente expresados en la morfología urbana, donde se detectaba a priori la existencia de la madina amurallada de los siglos XV-XVI, las fortificaciones españolas del siglo XVII, la planificación urbanística del XVIII, todo ello condicionado por la existencia de enclaves defensivos militares, $y$ una zona de ensanche llevada a cabo en el siglo $X X$ con una destacada arquitectura asentada sobre unos esquemas urbanísticos planificados.

3. El ajustado tamaño de la ciudad y de su Centro Histórico hacían también viable realizar un estudio que, respondiendo a los objetivos del proyecto de investigación, permi- 


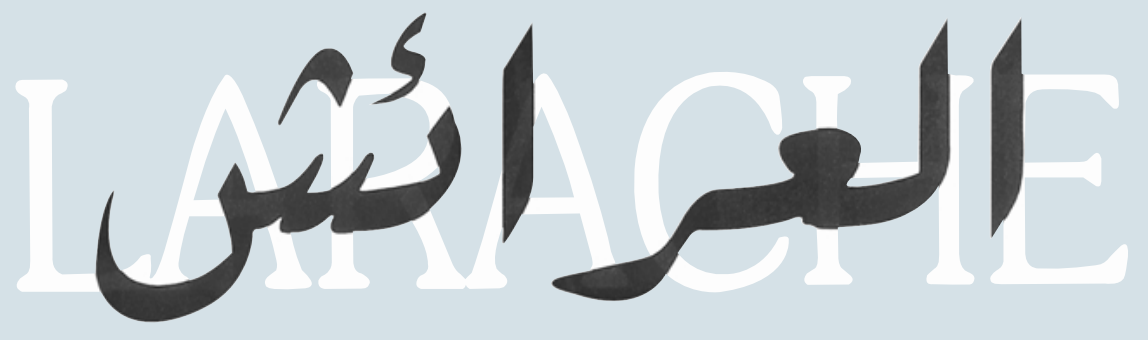

tiera analizar gran cantidad de situaciones y problemas diferentes, primando la diversidad frente a la extensión, con el consiguiente interés que lleva aparejado esta circunstancia.

4. La inexistencia de trabajos similares sobre Larache hacía encontrarnos con un territorio en cierto modo virgen, donde las posibilidades estaban por determinar, aunque por otro lado la falta de iniciativas anteriores podía suponer una desventaja.

Desde los primeros pasos decidimos entender el concepto de centro histórico en su sentido más amplio, de forma que en el caso de Larache es necesario considerar también como tal la parte del ensanche edificada hasta los años cincuenta de la pasada centuria, debido a sus especiales cualidades arquitectónicas y urbanísticas. Es por ello que nos referiremos como Ciudad Antigua a la que fue ocupando y pervivió hasta finales del siglo $X I X$ dentro del amplio recinto que abarcaban las murallas del siglo XVII, y como Ciudad Moderna o Ensanche a la que se planificó y construyó durante el protectorado español en Marruecos en la primera mitad del siglo $X X$.

\section{Metodología}

Cabe entender dos grandes estadios en el proceso. Uno primero ha sido dirigido a la comprensión de la realidad física del objeto de estudio y a los criterios culturales, sociales, económicos, políticos, etc, que lo originaron en su momento, lo mantienen y tensionan en la actualidad, y son capaces de transformarlo en el futuro. Esta primera parte nos ha permitido detectar, además, en gran medida el conjunto de problemas de toda índole que afectan al centro histórico, las necesidades que la sociedad que los habita demanda de ellos y los medios con los que cuentan para satisfacer esas deman- das. Este primer estadio ha originado una documentación que forma una parte importante del cuerpo físico del trabajo de investigación.

El segundo estadio trata de aportar un conjunto de medidas ordenadas según unas directrices que, aunque generales, descienden a soluciones concretas a problemas individualizados en el proceso de análisis.

Hay que tener en cuenta que simplemente trazar una cartografía actualizada de la madina de Larache ha sido, pensamos, un logro en sí mismo; que el concepto de propiedad privada-propiedad pública es bastante diferente al que tenemos grabado en nuestros esquemas; que lo que para la experiencia andaluza puede ser un centro histórico, entendido como único depositario de lo pasado, para el habitante de las ciudades del Maghreb es realmente la madina, la ciudad, y que por lo tanto es un bien que representa 10 presente. En otras palabras, lo que para nuestra forma de pensar es un objeto de estudio presentación gráfica y la normativa (con toda nuestra carga teórica, legal, metodológica y económica que ello supone), para la suya es un bien de uso cotidiano que han de utilizar intensamente, que siendo depositario de lo pasado lo es en mayor medida de lo presente, que no hay que recuperar porque todavía no se ha perdido, pero que empieza a sufrir unas presiones de índole demográfica, económica y social que hace necesario el planteamiento de directrices válidas y cercanas a su realidad.

La investigación contribuye además a la puesta en valor de un patrimonio urbano, en este caso arqueológico, relativo a las preexistencias en la zona objeto de estudio. Concretamente se plantea un avance de carta de riesgo para la gestión de los bienes culturales en medio urbano para proteger el patrimonio arqueológico en determinados lugares de y de recuperación, controlado desde la re- la ciudad y su entorno próximo donde la investigación sobre la ocupación histórica pueda facilitar el conocimiento sobre los orígenes de su fundación, localización de estructuras, etc.

Otra de las aportaciones del trabajo de investigación sobre Larache ha sido la recopilación del mayor número de fuentes bibliográficas, documentales y cartográficas posible. Con ello se sintetiza una dispersísima serie de datos de toda índole que además necesitaban se revisados y actualizados en mayor o menor medida.

Tras el estudio de toda la información, obtenida tanto por fuentes documentales, bibliografía y colaboradores, así como por la propia experiencia del trabajo de campo y la encuesta activa, la realidad del centro histórico de Larache ha podido ser dibujada. Los resultados del proyecto de investigación nos permiten comprobar los numerosos procesos de degradación que afectan a la Ciudad Antigua de Larache. Teniendo en cuenta los fines de nuestro trabajo, se ha procedido a fijar sobre ella una serie de objetivos sintetizados como orientaciones para la intervención, con las que se ha intentado, al menos, diseñar una base de partida y unas propuestas, lógicamente debatibles, de cara a futuras intervenciones que se acometan.

La iniciativa de la Dirección General de Urbanismo y Ordenación del Territorio de la Consejería de Obras Públicas y Transportes en el marco de la cooperación andaluza en la zona norte de Marruecos, ha facilitado a este equipo la continuación de estos trabajos de investigación que han tenido su continuidad en Chefchauen (años 2000-200I) y Tetuán (en ejecución). De este modo, además de las posibilidades intrínsecas que tiene la propia investigación actualizada sobre los centros históricos del Magreb, ha propiciado una mayor fluidez en las relaciones sociales e institucionales de ambas comunidades a la vez que se ha ido ampliando el conocimiento mutuo y el intercambio cultural y científico.

Guillermo Duclós Bautista Arquitecto

Pedro Campos Jara Arqueólogo 